\title{
Primary Leiomyosarcoma of Skin: A Report and Critical Appraisal
}

\author{
JOHN T. HEADINGTON, THEODORE F. BEALS AND JOHN E. NIEDERHUBER
}

Department of Pathology, The University of Michigan Medical School, Ann Arbor, Michigan, U.S.A.

\begin{abstract}
A primary leiomyosarcoma of skin was studied by light and electron microscopy and by histochemistry. Systematic evaluation of the entire neoplasm suggested that a single biopsy sample would show little cellular pleomorphism but could vary considerably in number of mitoses per $\mathrm{mm}^{2}$. Electron microscopy revealed a high degree of cytologic differentiation. Strong myosin ATPase activity and negative demonstrations for hydrolytic enzymes suggest a diagnostic profile which will clearly separate this neoplasm from malignant fibrous histiocytoma. High mitoses counts, the conventional criterion for malignancy of non-cutaneous smooth muscle tumors, may not be appropriately applied to primary leiomyosarcomas arising in the dermis. The findings in this case and a critical review of the literature suggest that reliable criteria for diagnosis of primary cutaneous leiomyosarcoma by light microscopy remain to be established.
\end{abstract}

(Received for publication July 23, 1977)

For diagnostic and therapeutic purposes it is important to know if the natural histories of primary soft tissue tumors of the skin are similar to homologous neoplasms arising in other tissues. Several different malignant soft tissue tumors may involve the skin. A partial list includes: angiosarcoma, epithelioid sarcoma, leiomyosarcoma, liposarcoma, neurofibrosarcoma, rhabdomyosarcoma, synovial cell sarcoma, and malignant fibrous histiocytoma. Some of these neoplasms commonly, if not always, arise in either superficial or deep soft tissues and secondarily invade the dermis. Notable examples of the latter are rhabdomyosarcoma and liposarcoma, as well as epithelioid and synovial sarcomas. Others, however, may clearly originate in the dermis: angiosarcoma, leiomyosarcoma, and malignant fibrous histiocytoma.

The rarity of these neoplasms, as well as differences in modes of study found in various reports, makes retrospective evaluation of the literature very difficult. At the very least, however, the assumption should not be made that the criteria for diagnosis and the histiologic findings related to prognosis are necessarily the same for primary cutaneous sarcomas as for tumors of the same type arising elsewhere.

The purpose of this paper is to present the detailed morphologic findings of a recurrent and locally aggressive smooth muscle tumor of skin; to critically view the reports of other such tumors and to relate these findings to diagnosis and treatment.

\section{Materials and Methods}

\section{Case Report}

A 49-year-old Caucasian woman was admitted to The University of Michigan Medical Center with a firm nodular mass in the right buttock. A lesion in this area had been biopsied for the first time more than 19 years before. There had been four local recurrences, each followed by an attempted excision. At this time there was a $3 \times 4 \mathrm{~cm}$ mass in the center of an old incisional scar which extended from the perianal area 
laterally up the buttock. Extensive evaluation disclosed no evidence for metastatic neoplasm.

Review of all the original biopsies revealed a diffusely infiltrating intradermal spindle cell neoplasm having the light microscopic characteristics of leiomyosarcoma. The lesion was again widely excised and the area grafted. Recovery was without incident.

\section{Light Microscopy}

The recurrent nodular tumor of the buttock was fixed in 10\% neutral buffered formalin. The specimen, divided into tissue blocks approximately $2 \mathrm{~mm}$ in thickness, was paraffin embedded. Selected sections were stained with each of the following: hematoxylin and eosin, Movat's pentachrome, Masson's trichrome and Wilder's reticulin.
A $1.0 \times 0.3 \mathrm{~cm}$ portion of the fresh tumor was flash frozen in isopentane chilled in liquid nitrogen. The specimen was sectioned immediately in a cryostat at $-15^{\circ} \mathrm{C}$. Enzyme histochemical demonstrations on coverslips were done according to standard controlled methods for succinic dehydrogenase, isocitric dehydrogenase, NADH diaphorase, lactate dehydrogenase, glucose 6-phosphate dehydrogenase, glucose 6-phosphatase, phosphorylase-brancher, non-specific esterase, beta glucose aminidase, beta glucuronidase, acid and alkaline phosphatase, and monoamine oxidase. Demonstrations for myosin ATPase were done at pH 3.5, 4.5, 5.5, 6.5, $7.5,8.5$, and 9.4 .

\section{Electron Microscopy}

Fresh tissue was prepared by mincing in

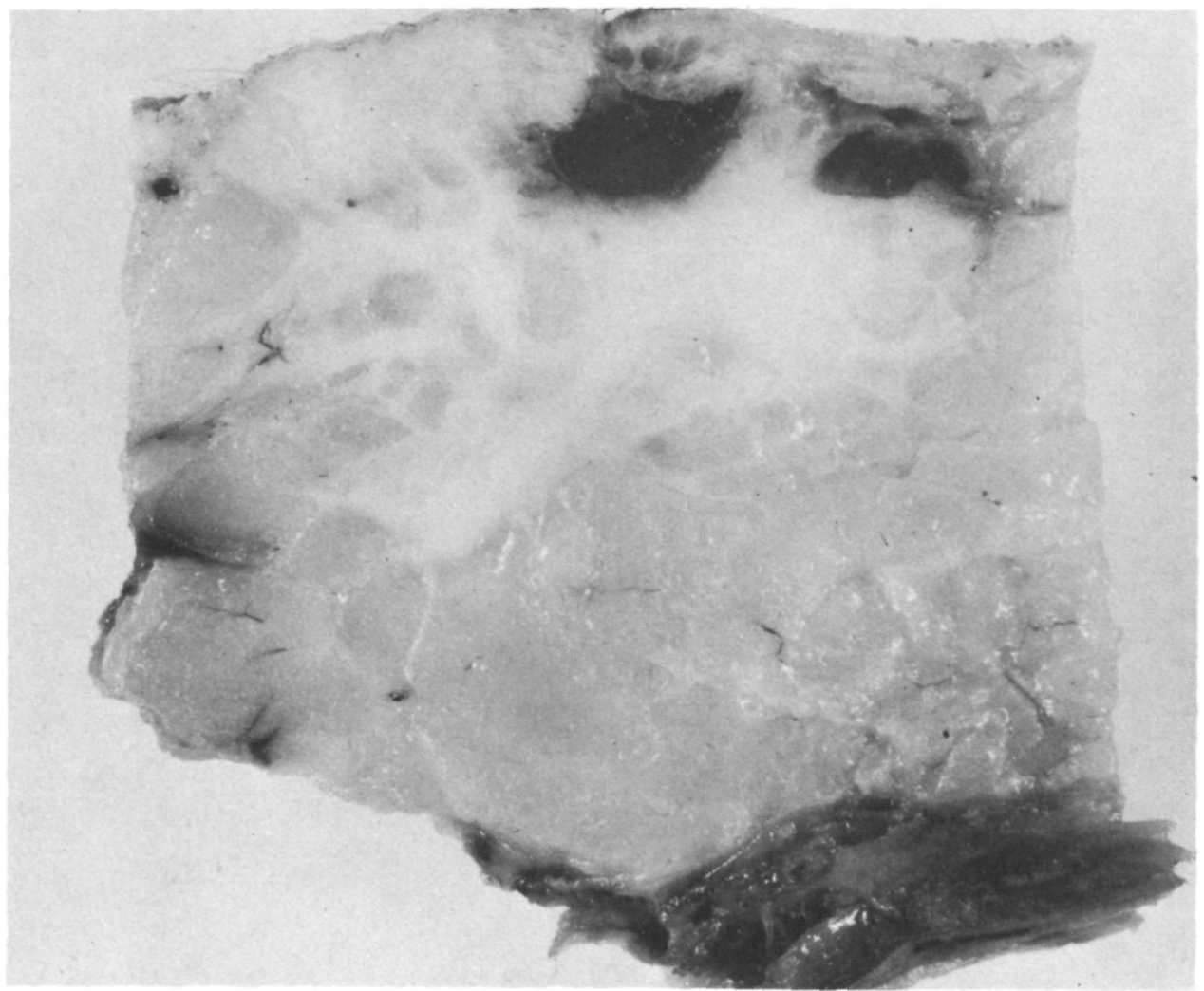

Fig. 1. Leiomyosarcoma. A diffusely infiltrative macroscopic pattern of growth is typical for primary leiomyosarcomas of skin. Dark spots are biopsy sites. 
freshly prepared $3 \%$ buffered glutaraldehyde pH 7.3. Fixed tissue was washed in three changes of Sorenson's buffer for $30 \mathrm{~min}$. Post-fixation was done in $1 \%$ osmium tetroxide buffered with collidin for $60 \mathrm{~min}$ at $4^{\circ} \mathrm{C}$. This step was followed by 3 washes of distilled water. Tissue was then stained en-bloc with aqueous uranyl acetate for $20 \mathrm{~min}$ at room temperature. Dehydration was done in graded ethanol and embedding completed in an Epon 812 - Araldite 592 mixture following propylene oxide. Ultrathin sections were stained with lead citrate and examined in a Zeiss transmission electron microscope.

Semiquantitative evaluations of cellular pleomorphism and direct counts of mitoses were done using a calibrated ocular micro- meter to measure a circular field exactly $0.25 \mathrm{~mm}$ in diameter (area, $0.049 \mathrm{~mm}^{2}$ ).

\section{Light Microscopy}

\section{Results}

The histologic features of the neoplasm were those of a moderately cellular spindle cell proliferation arrayed in dense interlacing fasicles. The interface between tumor and reticular dermis was permeative and infiltrative, not blunted or pushing (Fig. 1). Extension into deeper subcutaneous tissues was along the lines of the dermal retinacula and locally by extension of single spindled tumor cells into the interstices of individual fat cells (Fig. 2). Very little cellular or vascular reaction was evoked by tumor growth. Birefringent fibrils were readily

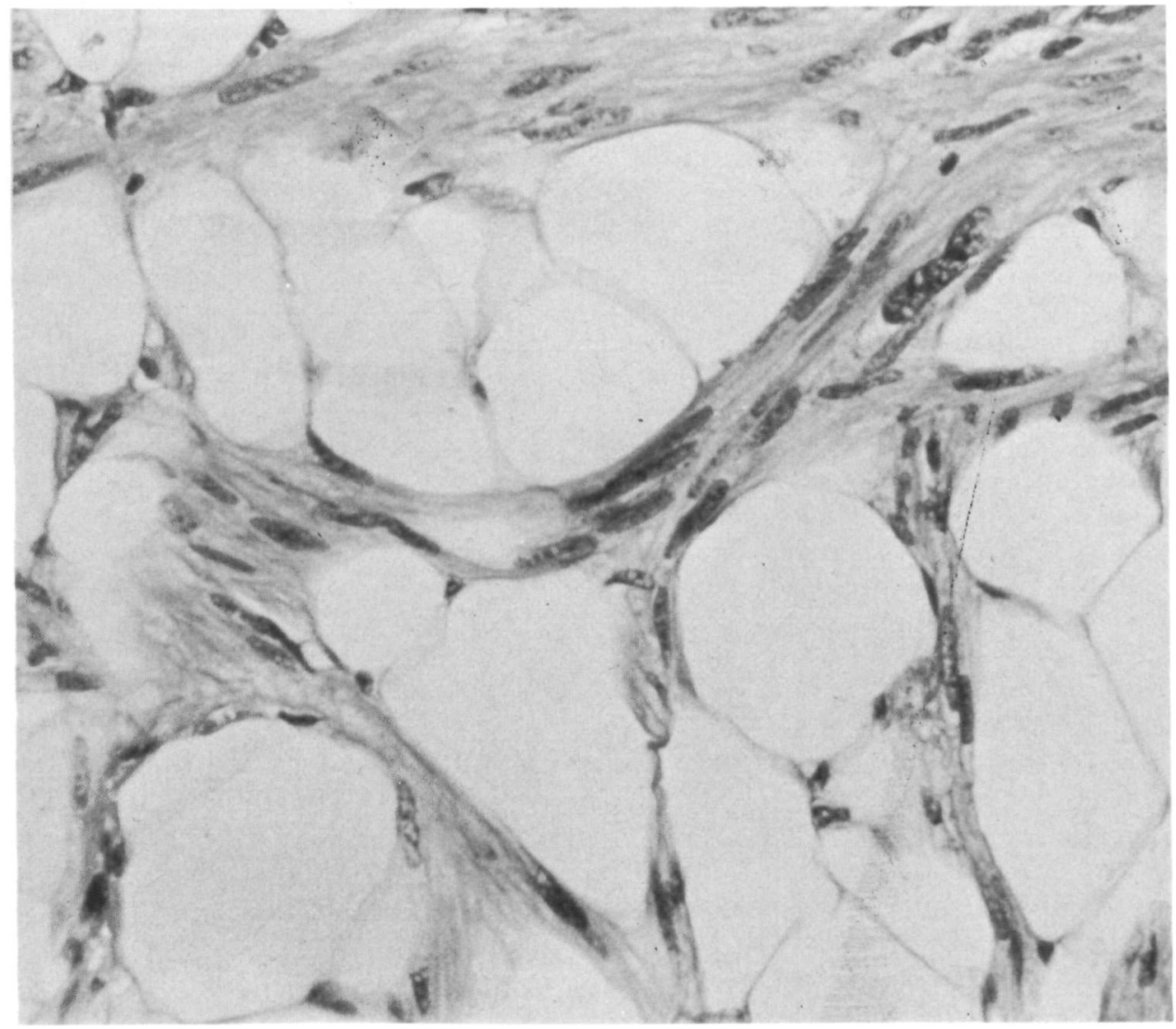

Fig. 2. Leiomyosarcoma. Deep extension of proliferating tumor cells is at first along the planes of the dermal retinacula and then locally between individual fat cells. Hematoxylin and eosin $\times 260$. 
demonstrated in the amphophilic cytoplasm of longitudinally oriented tumor cells by high-intensity polarization microscopy. Elongate blunt-ended nuclei with crisply detailed punctate chromatin contained small nucleoli (Figs. $3 \& 4$ ). Barr bodies were not readily identified.

Pleomorphism was judged on a $1-3$ scale: slight, 1 (Fig. 3); moderate, 2 (Fig. 4); marked, 3. Twenty fields of $0.049 \mathrm{~mm}^{2}$ or approximately $0.05 \mathrm{~mm}^{2}$ were evaluated. Only rare fields rated 2 while none rated 3 . Using this simple scale, the mean value for pleomorphism was equal to, or only slightly greater than, one for each of 30 different samples (different tissue sections).

The number of mitoses was counted for each of the 20 fields evaluated for pleomorphism. The total area per sample (each glass slide) therefore was very close to $1.0 \mathrm{~mm}^{2}$. The mean value was 12.5 mitoses per square millimeter (S.D. =6.1). The range was 4-36 mitoses per square millimeter.

\section{Histochemistry}

Histochemical reactions are detailed in Table 1. Strongly positive reactions were observed for all oxidative enzymes. Glucose 6-phosphatase demonstrations were rated as $2+$. Reactions for all hydrolytic enzymes were negative. Myosin ATPase preparations were most strongly positive $(4+)$ at $\mathrm{pH} \mathrm{7.5-8.5}$ (Fig. 5). A slight amount $(1-2+)$ of sudanophilic lipid was found. PAS stains of frozen sections were equivocal $( \pm)$.

\section{Electron Microscopy}

Ultrastructural details of tumor cells revealed

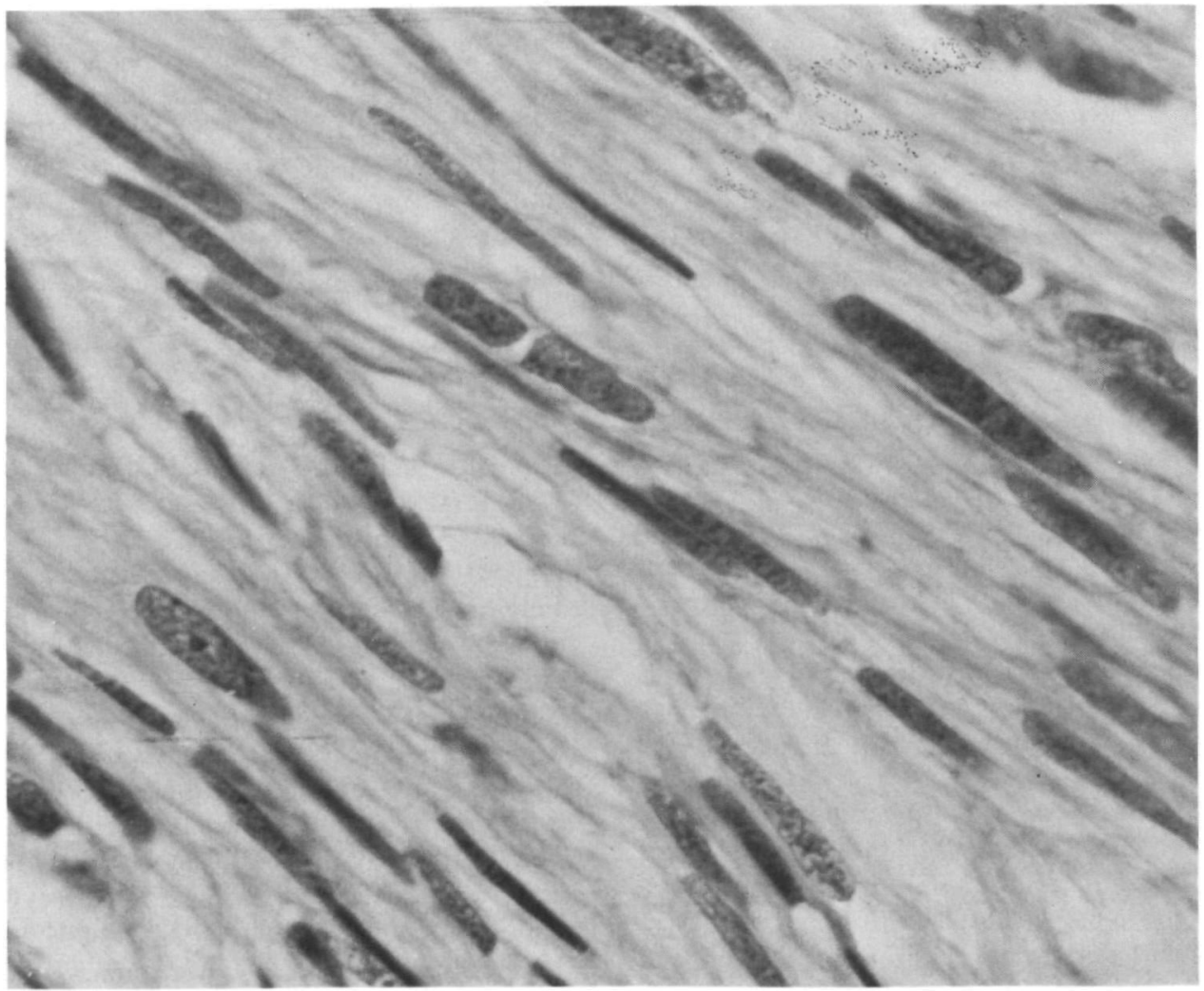

Fig. 3. Leiomyosarcoma. Nuclear detail in longitudinal section. Pleomorphism judged as slight $(1+)$. Compare with Fig. 4. Hematoxylin and eosin $\times 400$. 


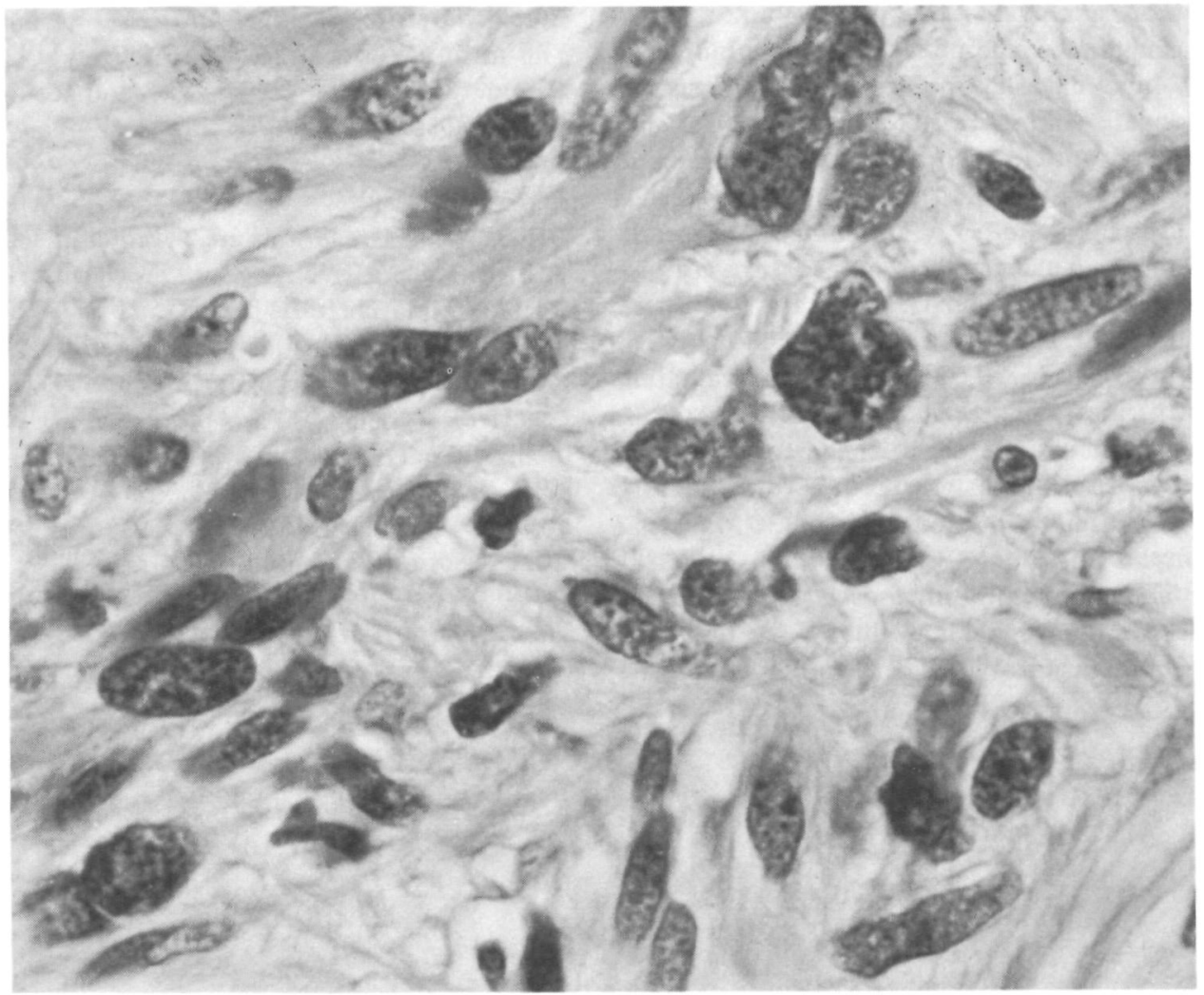

Fig. 4. Leiomyosarcoma. Nuclear detail in longitudinal section. Pleomorphism judged as moderate $(2+)$. Compare with Fig. 3. Hematoxylin and eosin $\times 400$.

Table 1

Enzyme Histochemical Studies: Leiomyosarcoma of Skin
Demonstration

NADH diaphorase (NADH)

Succinic dehydrogenase (SDH)

Lactate dehydrogenase (LDH)

Isocitric dehydrogenase (ICD)

Monoamine oxidase (MAO)

Phosphorylase-brancher

Myosin ATPase, $\mathrm{pH} 7.5-8.5$

Glucose 6-phosphate

dehydrogenase (G6-PD)

Glucose 6-phosphatase

Acid phosphatase

Alkaline phosphatase

Non-specific esterase

Beta glucose aminidase
Result

$3+$

$3+$

$4+$

$4+$

$2+$

$1+$

$4+$

$2+$

$-$

$-$

$-$

$-$ the major hallmarks of well-differentiated smooth muscle cells: thick and thin myofilaments, fusiform cytoplasmic densities, marginal densities along the cell membrane (marginal plaques), numerous pinocytic vesicles, and cellular basement membranes (Fig. 6).

Individual cells were fusiform with variable cell processes. Nuclei were variable with extensive lobation in some cells. Occasional intranuclear cytoplasmic islands were found. Swollen mitochondria with lamellar cristae were distributed throughout the cytoplasm or congregated in polar aggregates.

Junctional complexes were uncommon but were usually found at the ends of short blunt cell processes. These were most 


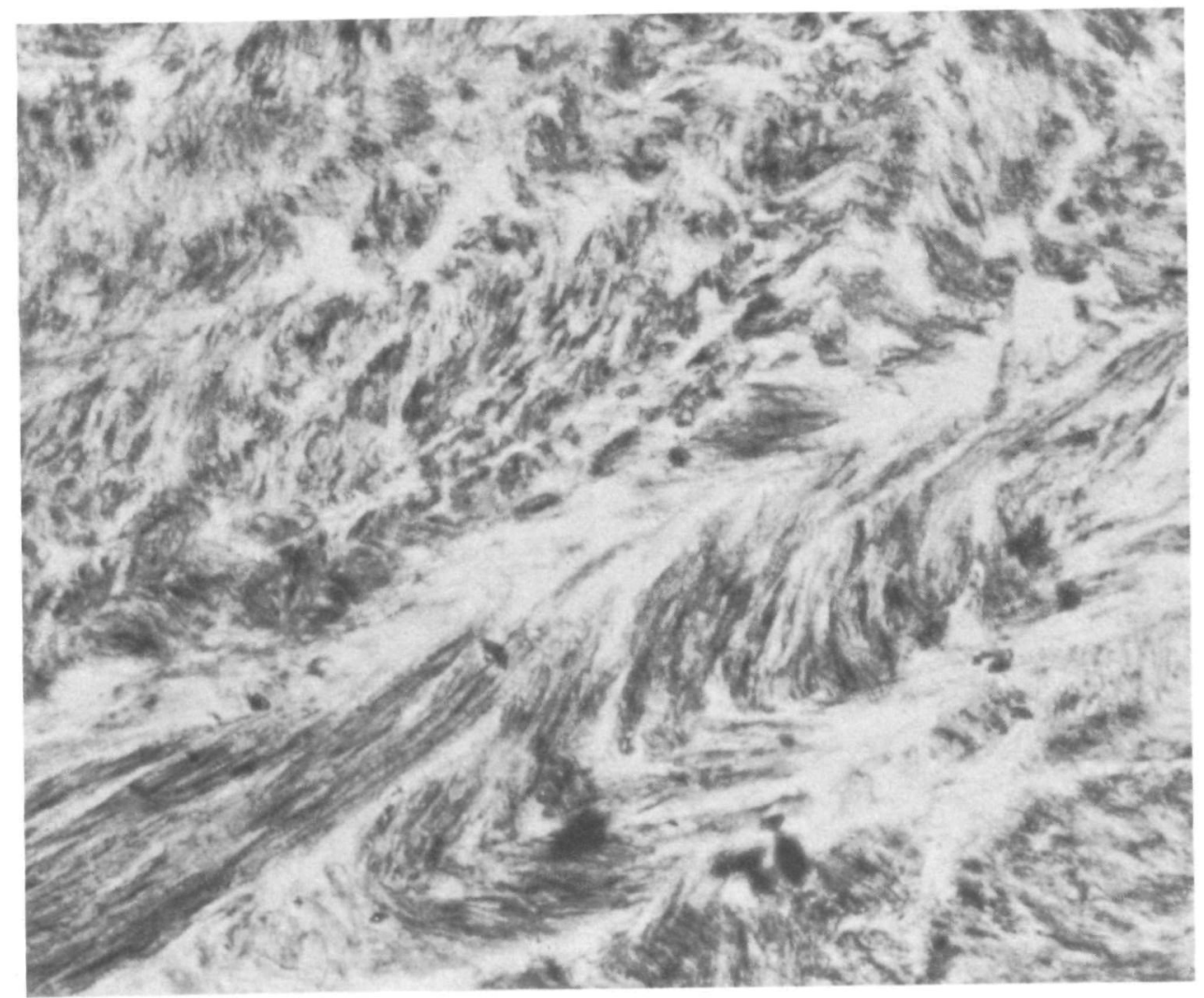

Fig. 5. Leiomyosarcoma. There is abundant myosin ATPase activity at pH 7.5-8.5. Frozen section $\times 260$.

frequently of intermediate type (gap junctions).

\section{Discussion}

This primary smooth muscle tumor of skin could readily be classified as a leiomyosarcoma according to the conventional criteria advanced by Stout \& Hill (1958); i.e., (1) size greater than $2.5 \mathrm{~cm}$ in diameter; (2) a mitotic rate averaging 10 per 10 high power fields in cellular areas.

The putatively reliable subjective criteria for recognition of malignancy of certain tumors of soft parts by routine light microscopy are notoriously difficult to learn and to teach. It is not surprising therefore that mitosis counting, however crudely done in the guise of quantitative data, has proved alluring to those investigating tumors of smooth muscle.
Mitosis counts greater than 10 mitoses per 10 high power fields have been used as the sole criterion for diagnosis of malignancy in tumors of uterine smooth muscle (Kempson 1976). And Stout \& Hill (1958), in a study of leiomyosarcomas of superficial soft tissues stated that, 'if mitoses can be found at an average rate of one or more per every 5 high power fields $(\times 200)$, the tumor is almost certainly malignant.' That such values are not a sine qua non was underscored by these same authors who also recorded metastases as occurring in four of 19 leiomyosarcomas of superficial soft tissues in which the mitotic rate was only 1 in 10 or more high power fields.

Unlike smooth muscle neoplasms of uterus and gut which often tend to be removed and studied in toto, smooth muscle tumors of skin are at first usually only 


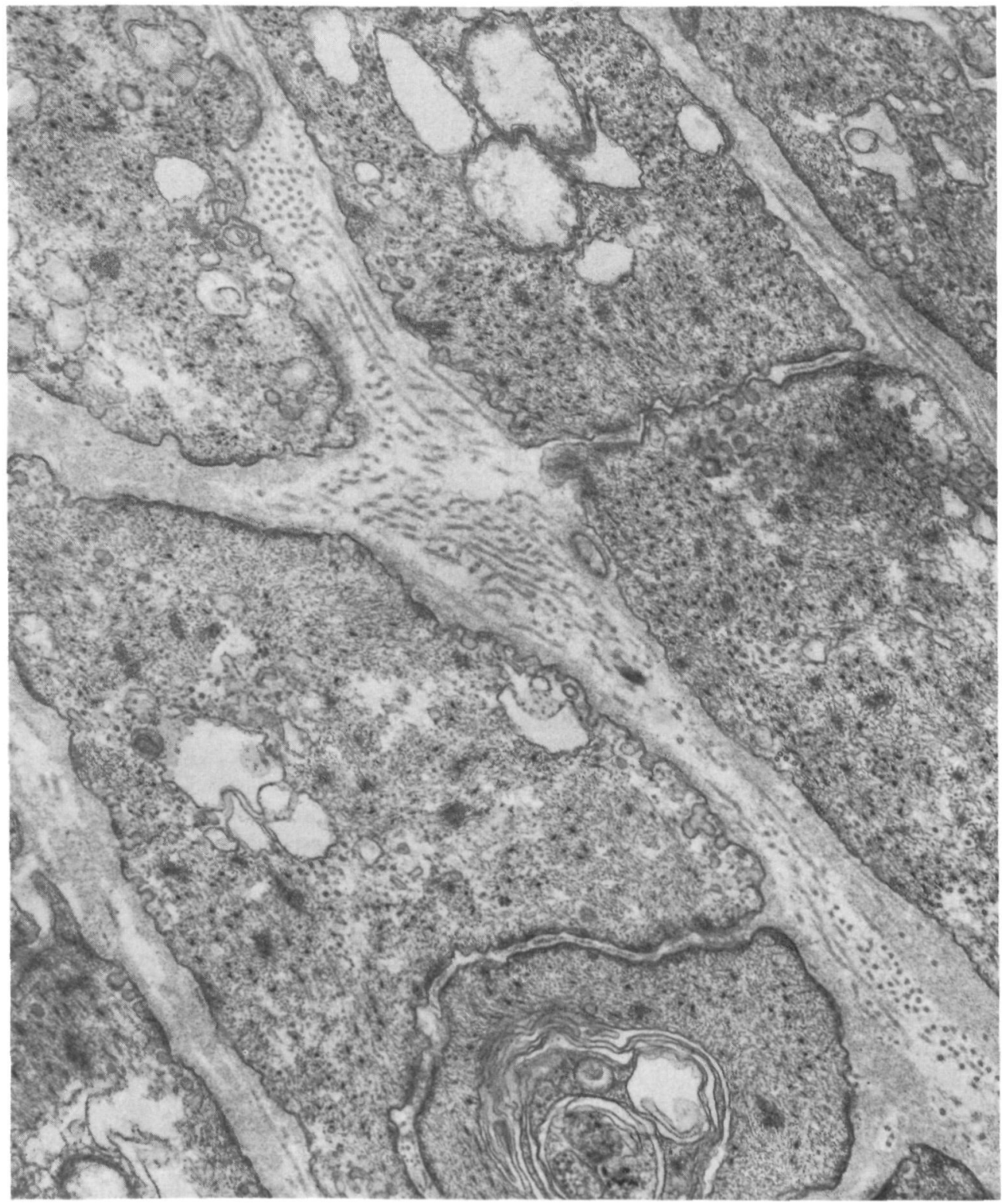

Fig. 6. Leiomyosarcoma. Electron microscopic view of tangent sections of tumor cells shows numerous regularly dispersed fusiform cytoplasmic densities and many pinocytotic vesicles. $\times 9500$. 
sampled by biopsy. It has undoubtedly been assumed that such biopsy samples are representative. Therapeutic strategies may then be based on this assumption of uniformity. The hypothesis of sample uniformity in the neoplasm was tested by embedding and sectioning the entire specimen at thickness intervals of $2 \mathrm{~mm}$.

Quantitative studies of the degree of pleomorphism and of the number of mitotic figures were determined for an area of one square millimeter. It was then found that cellular pleomorphism varied only slightly from area to area.

A more important question was the uniformity of the mitotic counts. Statistically, there was a non-uniform distribution of mitotic counts. This suggested the presence of mitotic 'hot spots' which might not be represented in single samples. In this neoplasm a range of 4-36 mitoses per square $\mathrm{mm}$ were counted in different histologic sections of the same tumor. This refinement of mitosis counting by counting a measured area should make future comparisons more exact. Nevertheless, it is important to realize that although these data have been acquired with some precision and have been statistically analyzed, they are essentially meaningless as far as providing an accurate predictive view of the natural history of the clinically aggressive and recurrent primary smooth muscle tumor of skin is concerned. For, other than by homology, there is no justification for assuming that data acquired for malignant primary smooth muscle tumors in the uterus, gut or non-cutaneous superficial soft tissues can be meaningfully transposed to malignant primary smooth muscle tumors of the dermis.

This cautionary view is partially substantiated by a recent observation that the conventional light microscopic criterion for malignancy, i.e., mitosis count, in smooth muscle tumors does not necessarily correlate with ultrastructural features of cellular differentiation. McGregor \& Liu (1975), in a comparative light and electron microscopic study of a cutaneous leiomyosarcoma of 30 years duration, found well differentiated smooth muscle cells similar to those seen in leiomyomas. In parallel with this, the ultrastructural findings in the neoplasm recorded in our study also revealed features of well differentiated smooth muscle cells: formation of distinct basement membranes, marginal dense bodies (plaques), numerous pinocytotic vesicles, abundant myofilaments parallel to the long axis of the cell, and numerous cytoplasmic dense bodies.

Nevertheless, discrepancy between conventional criteria for malignancy and ultrastructural differentiation of leiomysosarcomas is apparently not a predictable occurrence. All of the ultrastructural features of well-differentiated smooth muscle cells detailed above were found in only six of 11 leiomyosarcomas of varied locations studied by Morales et al. (1975), although it should be noted that none of the neoplasms examined by these authors was primary in the skin.

To our knowledge, previous accounts of leiomyosarcomas of skin and superficial soft tissues do not include enzyme histochemical studies. The presence of abundant myosin ATPase and the virtual absence of lysosomal hydrolytic enzymes would suggest a specific if not diagnostic enzymatic profile. Primary malignant fibrous histiocytomas of skin (two examples studied by us), which can also present as interlacing fasicles of spindled cells within dermis, demonstrate the opposite set of enzymatic reactions: abundant lysosomal hydrolytic enzymes and absent myosin ATPase activity ( $\mathrm{pH} 7.5-8.5)$.

Detailed review of previously published well-documented cases of primary cutaneous leiomyosarcoma (Table 2) failed to contribute to an understanding of morphologic criteria required for diagnosis of malignancy. None of the tabulated cases was confirmed or studied by electron microscopy.

An additional nine cases, other than those tabulated, have been published since 1936 (Bartkowiak 1936, Levack \& Dick 1955, Rising \& Booth 1966, Pendse \& Saxena 1969, Haim \& Gellei 1970, Chaves et al. 1972, Dupperat et al. 1973). In some of these it was not possible to determine if 
Table 2

Summary of Cases of Primary Leiomyosarcoma of Skin

\begin{tabular}{|c|c|c|c|c|c|c|c|c|c|}
\hline Case & Date & & Age & Sex & Site & Size & Duration & Metastases & Follow-up \\
\hline 1 & 1955 & Kilgour & 29 & $\mathrm{~F}$ & Back & $2 \mathrm{~cm}$ & $2 \mathrm{yrs}$ & - & $<1 \mathrm{yr}$ \\
\hline 2 & 1959 & $\begin{array}{l}\text { Montgomery \& } \\
\text { Winkelmann }\end{array}$ & 32 & $\mathrm{~F}$ & Thigh & $1 \mathrm{~cm}$ & - & - & $21 \mathrm{yrs}$ \\
\hline 3 & 1960 & $\begin{array}{l}\text { Tappeiner \& } \\
\text { Wodniansky }\end{array}$ & 70 & M & Chest & $8.7 \mathrm{~cm}$ & $3 \mathrm{yrs}$ & - & - \\
\hline 4 & 1962 & $\begin{array}{l}\text { Daoud \& } \\
\text { Mascaro }\end{array}$ & 50 & M & Shoulder & $10 \times 10$ & $4 \operatorname{mos}$ & - & - \\
\hline 5 & 1967 & $\begin{array}{l}\text { Panabokke \& } \\
\text { Attygalle }\end{array}$ & 40 & $\mathrm{~F}$ & Buttock & $2 \mathrm{~cm}$ & $15 \operatorname{mos}$ & - & - \\
\hline 6 & 1971 & Smith & 58 & M & Back & $3 \times 3 \times 2.5$ & 5 yrs & - & - \\
\hline 7 & 1977 & $\begin{array}{l}\text { Headington } \\
\text { et al. }\end{array}$ & 49 & $\mathrm{~F}$ & Buttock & $3 \times 4$ & 19 yrs & - & $<1 \mathrm{yr}$ \\
\hline
\end{tabular}

the primary tumor was intradermal. In several others the histologic findings are not convincing by contemporary standards or were not illustrated. A total cumulative series would probably represent a heterogeneous group of spindle cell neoplasms including some malignant fibrous histiocytomas as suggested by the cases described by Levack \& Dick (1955), and by Haim \& Gellei (1970).

Three review series of leiomyosarcomas of superficial soft tissues have been published, including the initial series of 36 cases by Stout \& Hill (1958); a report of 10 cases by Phelan et al. (1962); and a recent clinicopathologic study of 47 cases by Dahl \& Angervall (1974). Stout \& Hill (1958) and Phelan et al. (1962) did not separate and compare tumors arising from the dermis from those arising in other superficial sites. Dahl \& Angervall (1974) found 19 patients with tumors arising entirely or almost entirely within the dermis but did not describe the clinical or morphologic details of those patients and did not indicate their criteria for malignancy.

Although lymph node metastases have been reported in three cases of primary cutaneous leiomyosarcoma (Levack \& Dick 1955, Haim \& Gellei 1970), in each of these the initial tumor was composed of circumscribed nodules, while cytologically these cases also contained multinucleate giant cells. Both of these features are entirely consistent with spindled malignant fibrous histiocytomas. None was examined ultrastructurally. There is reasonable doubt therefore about the nosologic accuracy of these reports.

It must be concluded that reliable guidelines for the diagnosis of malignancy of primary smooth muscle tumors of skin by routine light microscopy have not yet been established. High mitosis counts have been found in two well-differentiated neoplasms proved by electron microscopy. There is no carefully documented example (enzyme histochemistry and/or electron microscopic studies) of a primary leiomyosarcoma of skin which has metastasized. These considerations would suggest that, until further data are acquired, the appropriate therapeutic strategy for a locally aggressive 'histologically malignant' primary smooth muscle tumor of skin should be local excision without elective lymph node dissection.

\section{References}

Bartkowiak, Z. (1936) Ein Fall von Sarcoma leiomyoblasticum der Haut. Zentralblatt fur Allgemeine Pathologie und Pathologische Anatomie $65,179-180$.

Chaves, E., Sá, H., Gadelha, N. \& Vasconcelos, E. (1972) Leiomyosarcoma in the Skin. Acta Dermato-Venereologica 52, 288-290.

Dahl, I. \& Angervall, L. (1974) Cutaneous and subcutaneous leiomyosarcoma. A clinicopathologic study of 47 patients. Pathologia Europaea 9, $307-315$. 
Daoud, R. \& Mascaro, J.M. (1962) Léiomyosarcoma primitif de la peau: Rapport d'un cas personnel. Societé Française de Dermatologie et de Syphilographie Bulletin 69, 526-533.

Duperrat B., Gueguen, H. \& Marvelle, J. (1973) Léiomyosarcome cutané. Tumor unique à évolution lenti. Société Française de Dermatologie et de Syphilographie Bulletin 80, 462-464.

Haim, S. \& Gellei, B. (1970) Leiomyosarcoma of the skin. Report of two cases. Dermatologica $140,30-35$.

Kempson, R. L. (1976) Mitosis counting - II. Human Pathology 7, 482-483.

Kilgour, C. S. (1955) Cutaneous Ieiomyosarcoma. British Journal of Plastic Surgery 8, 144-146.

Levack, J. \& Dick, A. (1955) Cutaneous leiomyosarcoma with lymphatic spread: A report of two cases. Glasgow Medical Journal 36, 337342.

McGregor, D. H. \& Liu, P. I. (1975) Cutaneous leiomyosarcoma of 30 years' duration: Electron Microscopic and tissue culture ultrastructural findings. Laboratory Investigation 32, 451.

Montgomery, H. \& Winkelmann, R. K. (1959) Smooth muscle tumors of the skin. Archives of Dermatology 79, 32-40.

Morales, A. R., Fine, G., Pardo, V. J. \& Horn, R. C. Jr. (1975) The ultrastructure of smooth muscle tumors with a consideration of the possible relationship of glomangiomas, hemangiopericytomas, and cardiac myxomas. Pathology
Annual, pp. 65-92. ed. Sommers, S. C. New York, Appleton-Century-Crofts.

Panabokke, R. C. \& Attygalle, L. S. (1967) Leiomyosarcoma of the skin. British Journal of Dermatology 79, 305-306.

Pendse, A. K. \& Saxena, O. (1969) Superficial leiomyosarcoma-report of a case. Indian Journal of Pathology and Bacteriology 12, $120-121$.

Phelan, J. T., Sherer, W. J. \& Mesa, P. (1962) Malignant smooth-muscle tumors (leiomyosarcomas) of soft-tissue origin. New England Journal of Medicine 266, 1027-1030.

Rising, J. A. \& Booth, E. (1966) Primary leiomyosarcoma of the skin with lymphatic spread. Archives of Pathology 81, 94-96.

Smith, L. J., Jr. (1971) Tumors of the Corium. In The Skin. ed. Helwig, E. B. \& Mostofi, F. K. pp. 533-557. Baltimore, Williams \& Wilkins.

Stout, A. P. \& Hill, W. T. (1958) Leiomyosarcoma of the superficial soft tissues. Cancer 11,884854.

Tappeiner. J. \& Wodniansky, P. (1960) Solitäres leiomyom-leiomyosarkom. Hautartz 11, 160163.

Address:

John T. Headington, M.D.

Department of Pathology

1335 E. Catherine Street

Ann Arbor, Michigan 48109

U.S.A. 
This document is a scanned copy of a printed document. No warranty is given about the accuracy of the copy. Users should refer to the original published version of the material. 